\title{
UCT-MBR vs IFAS-UCT-MBR for Wastewater Treatment: A Comprehensive Comparison Including $\mathrm{N}_{2} \mathrm{O}$ Emission
}

\author{
G. Mannina ${ }^{1(\bowtie)}$, M. Capodici ${ }^{1}$, A. Cosenza $^{1}$, D. Di Trapani ${ }^{1}$, \\ G.A. Ekama ${ }^{2}$, and H. Ødegaard ${ }^{3}$ \\ ${ }^{1}$ Dipartimento di Ingegneria Civile, Ambientale, Aerospaziale, dei Materiali, \\ Università di Palermo, Viale delle Scienze, Ed. 8, 90100 Palermo, Italy \\ \{giorgio. mannina, marco. capodici, alida. cosenza, \\ daniele.ditrapani\}@unipa.it \\ ${ }^{2}$ Water Research Group, Department of Civil Engineering, \\ University of Cape Town, Rondebosch, Cape Town 7700, South Africa \\ george.ekama@uct.ac.za \\ 3 Department of Hydraulic and Environmental Engineering, \\ NTNU - Norwegian University of Science and Technology, \\ 7491 Trondheim, Norway \\ hallvard. odegaard@ntnu.no
}

\begin{abstract}
In this study the performance (in terms of carbon and nutrient removal) and $\mathrm{N}_{2} \mathrm{O}$ emission of two plant configurations adopting innovative technologies were investigated. With this regards, an University Cape Town (UCT) membrane bioreactor (MBR) plant and an Integrated Fixed Film Activated Sludge (IFAS) -UCT-MBR plant were monitored. Both plants treat real wastewater under two different values of the influent carbon nitrogen ratio $(\mathrm{C} / \mathrm{N}=5 \mathrm{mgCOD} / \mathrm{mgN}$ and $\mathrm{C} / \mathrm{N}=10 \mathrm{mgCOD} / \mathrm{mgN})$. Results have shown the highest carbon and nutrients removal efficiencies for the IFAS-UCT-MBR configuration during both the two investigated $\mathrm{C} / \mathrm{N}$ values. Furthermore, the lowest $\mathrm{N}_{2} \mathrm{O}$ emission occurred for the IFAS-UCT-MBR.
\end{abstract}

Keywords: WWTP · Nutrient removal · Greenhouse gases $\cdot$ Global warming · Biofilm

\section{Introduction}

Nitrogen (N) and phosphorus (P) compounds (nutrients), discharged with wastewater, could seriously affect the quality of receiving water bodies, since their presence favours eutrophication and can be toxic for the aquatic organisms (Wang et al. 2006). Therefore, their removal from wastewater is an imperative requirement. With this regards, biological nutrient removal (BNR) processes have been largely explored, since they have the advantage of avoiding the use of chemicals compared with chemical processes. Despite conventional activated sludge (CAS) processes are effective for removal of organic and nutrients compounds, the overall efficiency is strictly depending on the final settler operation (Wanner 2002). Therefore, in the last years new and 
innovative technologies have been investigated in order to overcome the main drawbacks of the CAS systems and meet stricter water quality effluent limits. In this context, membrane bioreactor (MBR) technology guarantees higher effluent standard and has also the advantage of making the efficiency of the biological processes independent from the biomass settling properties.

Among the new technologies, it is notwithstanding to mention the moving bed biofilm reactors (MBBR), where biomass grows as biofilm on small plastic carrier elements, and MBBR-based Integrated Fixed Film Activated Sludge (IFAS) reactors, where biomass grows both as suspended flocs and as biofilm. When IFAS systems are combined with a MBR (realizing an IFAS-MBR) there is the potential to gain the best characteristics of both biofilm processes and membrane separation. IFAS - MBR reactors are especially useful when slowly growing organisms as nitrifiers have to be maintained inside a WWTP limiting the required reactor volumes due to the coexistence of both suspended biomass and biofilm and membrane separation. Although MBR and IFAS-MBR systems have several advantages with respect to CAS, they are characterized by specific peculiarities, which would strongly influence greenhouse gas (GHG) production/emission (mainly nitrous oxide, $\mathrm{N}_{2} \mathrm{O}$ produced during the BNR processes). For example, the intensive aeration for fouling mitigation in $\mathrm{MBR}$ can promote the $\mathrm{N}_{2} \mathrm{O}$ stripping. However, very few studies have been performed with this concern in biofilm and MBR systems (Todt and Dörsch 2016; Mannina et al. 2017). Therefore, further investigations are required in order to identify the key operating factors affecting the $\mathrm{N}_{2} \mathrm{O}$ emission from plants where advanced technologies are adopted. With this regards the main goal of this work is to investigate the performance (in terms of carbon and nutrient removal) and $\mathrm{N}_{2} \mathrm{O}$ emission of two plant configurations adopting innovative technologies: i. University Cape Town (UCT) MBR plant; ii. IFAS-UCT-MBR plant. Both plants treat real wastewater under two different values of the influent carbon nitrogen ratio $(\mathrm{C} / \mathrm{N}=5 \mathrm{mgCOD} / \mathrm{mgN}$ and $\mathrm{C} / \mathrm{N}=10 \mathrm{mgCOD} / \mathrm{mgN}$ ).

\section{Materials and Methods}

\subsection{Pilot Plants}

Two pilot plants were built at the Laboratory of Sanitary and Environmental Engineering of Palermo University. In particular, a University Cape Town (UCT) Membrane Bioreactor (MBR) and an Integrated Fixed Film Activated Sludge (IFAS) UCT-MBR were studied under two different values of the influent $\mathrm{C} / \mathrm{N}$ ratio. Both plants were characterized by identical reactors dimensions and lay-out. In particular, both pilot plants consisted of a $62 \mathrm{~L}$ stirred anaerobic reactor, a $102 \mathrm{~L}$ stirred anoxic reactor and a $221 \mathrm{~L}$ aerobic reactor, provided with fine bubble diffusers. In the membrane compartment was placed an ultrafiltration hollow fiber membrane module (Koch Puron ${ }^{\circledR} 3$ bundle) characterized by a pore size of $0.03 \mu \mathrm{m}$ and membrane net area of $1.4 \mathrm{~m}^{2}$. In the IFAS-UCT-MBR plant, suspended plastic carriers (Amitech®, $0.95 \mathrm{~g} \cdot \mathrm{cm}^{-3}$ and $500 \mathrm{~m}^{2} \mathrm{~m}^{-3}$ density and specific surface respectively) were placed into aerobic and anoxic reactor in order to reach a filling ratio equal to $40 \%$ and $15 \%$ 
corresponding to a net surface area equal to $200 \mathrm{~m}^{2} \cdot \mathrm{m}^{-3}$ and $75 \mathrm{~m}^{2} \mathrm{~m}^{-3}$ respectively. The anaerobic, anoxic, aerobic and MBR reactors were equipped with specific covers that made it possible to collect and sample the overall gas in the headspace from each compartment of the pilot plant.

\subsection{Influent Wastewater}

The pilot plant was fed with municipal wastewater mixed with a synthetic wastewater in order to control the $\mathrm{C} / \mathrm{N}$ ratio. The experimental campaign was divided into two phases, each characterized by a different $\mathrm{C} / \mathrm{N}$ value. The UCT-MBR plant was operated at the sludge retention time (SRT) value of 50 days (for $\mathrm{C} / \mathrm{N}=5 \mathrm{mgCOD} / \mathrm{mgN}$ ) and 40 days (for $\mathrm{C} / \mathrm{N}=10 \mathrm{mgCOD} / \mathrm{mgN}$ ). The IFAS-UCT-MBR plant was operated the SRT value of 65 days (for $\mathrm{C} / \mathrm{N}=5 \mathrm{mgCOD} / \mathrm{mgN}$ ) and 40 days (for $\mathrm{C} / \mathrm{N}=10$ $\mathrm{mgCOD} / \mathrm{mgN})$.

\subsection{Sampling and Monitoring Campaign}

The influent wastewater, the different reactors and the effluent permeate were sampled and analyzed for chemical oxygen demand (COD), biochemical oxygen demand (BOD), total nitrogen (TN), ammonium nitrogen $\left(\mathrm{NH}_{4}-\mathrm{N}\right)$, nitrate nitrogen $\left(\mathrm{NO}_{3}-\mathrm{N}\right)$, nitrite nitrogen $\left(\mathrm{NO}_{2}-\mathrm{N}\right)$, orthophosphate $\left(\mathrm{PO}_{4}-\mathrm{P}\right)$. All analyses were performed according to the APHA (2005).

The respirometric batch experiments were carried out on a "flowing gas/static-liquid" respirometer, according to the procedure described in literature (Mannina et al. 2017). Extracellular polymeric substances (EPSs) were extracted according to the procedure reported in literature (Cosenza et al. 2013; Mannina et al. 2016). The membrane fouling has been analysed according to the procedure reported in literature (Mannina et al. 2016).

Gas samples were collected from the funnel shape cover of the anaerobic, anoxic, aerobic and MBR reactors and transferred into glass vials and analysed with a gas chromatograph (GC). Air velocity was assessed by using a TMA 21HW Hot Wire anemometer in order to evaluate the gas flux. Liquid samples were collected from the anaerobic, anoxic, aerobic and MBR reactors and the dissolved $\mathrm{N}_{2} \mathrm{O}$ concentration was extracted by adopting the procedure proposed by Kimochi et al. (1998). The measured $\mathrm{N}_{2} \mathrm{O}$ concentrations were used to assess the $\mathrm{N}_{2} \mathrm{O}$ emission factor according to the procedure proposed by Tsuneda et al. (2005).

\section{Results and Discussion}

\subsection{Removal Performance}

Table 1 summarizes the average values of COD, $\mathrm{N}$ and $\mathrm{P}$ removal efficiencies. In terms of COD removal, data of Table 1 show that the solid liquid separation through the membrane allowed to maintain high total COD removal efficiency during each phase and for each plant configuration. However, the biological COD removal $\left(\eta_{\mathrm{BIO}}\right)$ was 
Table 1. Average removal efficiency values for each pollutant, plant configuration and experimental phase $(\mathrm{C} / \mathrm{N}=5$ and $\mathrm{C} / \mathrm{N}=10)$

\begin{tabular}{l|l|l|l|l|l}
\hline \multirow{2}{*}{ Symbol } & Description & \multicolumn{2}{l|}{ UCT-MBR } & \multicolumn{2}{l}{ IFAS-UCT-MBR } \\
\cline { 3 - 6 } & & $\mathrm{C} / \mathrm{N}=5$ & $\mathrm{C} / \mathrm{N}=10$ & $\mathrm{C} / \mathrm{N}=5$ & $\mathrm{C} / \mathrm{N}=10$ \\
\hline$\eta_{\text {TOT }}$ & Total COD removal efficiency & 98.47 & 98.31 & 98.06 & 98.59 \\
\hline$\eta_{\text {BIO }}$ & Biological COD removal efficiency & 73.58 & 83.03 & 79.50 & 84.01 \\
\hline$\eta_{\text {PHYS }}$ & Physical COD removal efficiency & 24.89 & 15.28 & 18.55 & 14.58 \\
\hline$\eta N_{\text {tot }}$ & Total N removal efficiency & 39.00 & 69.24 & 53.14 & 69.36 \\
\hline$\eta_{\text {nitr }}$ & Nitrification efficiency & 80.61 & 95.40 & 81.08 & 90.93 \\
\hline$\eta_{\text {denit }}$ & Denitrification efficiency & 32.27 & 56.25 & 42.78 & 52.02 \\
\hline$\eta_{\text {PO4 }}$ & PO $_{4}$-P removal efficiency & - & 71.82 & 67.16 & 87.50 \\
\hline
\end{tabular}

affected by the influent both by the plant configuration and influent $\mathrm{C} / \mathrm{N}$ value. Indeed, $\eta_{\mathrm{BIO}}$ increased with the increase of influent $\mathrm{C} / \mathrm{N}$. However, for the same $\mathrm{C} / \mathrm{N}$ value the highest $\eta_{\mathrm{BIO}}$ was obtained for the IFAS-UCT-MBR configuration. This result is mainly debited to the adding role in carbon removal due to the biofilm.

Similar results were found for the nitrogen removal; indeed, the simultaneous growth of biofilm in the aerobic and anoxic reactors was able to enhance the total nitrogen removal in the IFAS-UCT-MBR configuration even at the lowest $\mathrm{C} / \mathrm{N}$ value (at $\mathrm{C} / \mathrm{N}=5 \eta \mathrm{N}_{\text {tot }}$ was equal to $39 \%$ and $53.14 \%$ for UCT-MBR and IFAS-UCT-MBR configuration, respectively).

The attached biomass in the anoxic reactor has had a key role for the improvement of phosphorus removal under the lowest $\mathrm{C} / \mathrm{N}$ value. Indeed, as reported in Table 1 during the Phase at $\mathrm{C} / \mathrm{N}=5$ the phosphorus removal failed for the UCT-MBR configuration. This result was due to the COD limitation during denitrification, which caused that a great mass of $\mathrm{NO}_{3}-\mathrm{N}$ was pumped back from the anoxic to the anaerobic tank in the UCT-MBR scheme, thus disturbing the biological phosphorus removal mechanisms. Conversely, the contribution of biofilm (which does not compete for carbon with the suspended biomass) in the IFAS-UCT-MBR configuration allowed to improve phosphorus removal.

\subsection{Membrane Fouling}

Figure 1 shows the results of the total membrane resistance $\left(\mathrm{R}_{\mathrm{T}}\right)$. Data of Fig. 1 show an higher tendency of membrane to be fouled in the IFAS-UCT-MBR (Fig. 1b) configuration than UCT-MBR one (Fig. 1a). Indeed, five physical cleanings were required during the UCT-MBR configuration to maintain the $R_{T}$ value under the value suggested from manufactures. Conversely, nine physical and four chemical cleanings (adopting sodium hypochlorite) cleanings were required for the IFAS-UCT-MBR configuration. This result is likely debited to the increased sludge viscosity due to the biofilm. 

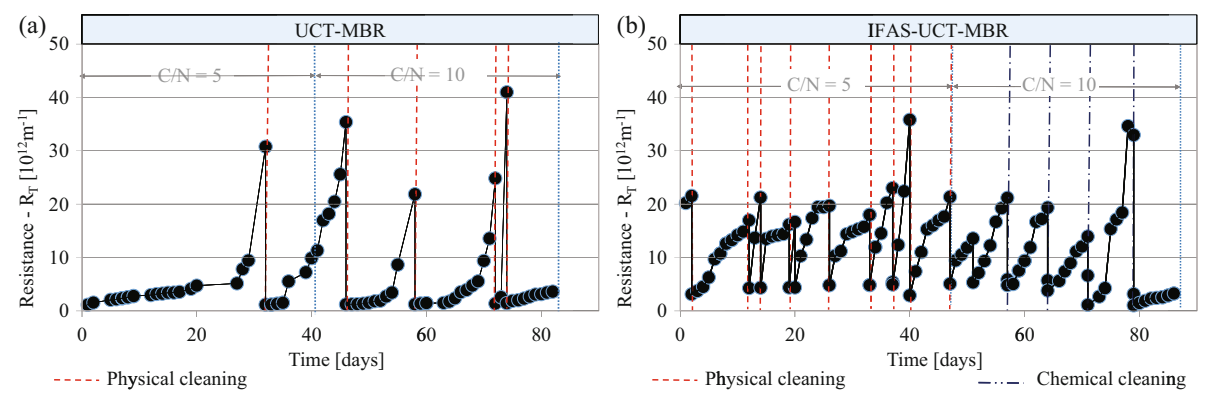

Fig. 1. Total membrane resistance $\left(\mathrm{R}_{\mathrm{T}}\right)$ for the UCT-MBR (a) and IFAS-UCT-MBR (b) configuration

\section{3 $\quad \mathrm{N}_{2} \mathrm{O}$ Emissions}

The average of the $\mathrm{N}_{2} \mathrm{O}$ emission factors (percentage of the influent nitrogen emitted as $\mathrm{N}_{2} \mathrm{O}$ ) for both plant configurations and influent $\mathrm{C} / \mathrm{N}$ values are depicted in Fig. 2.
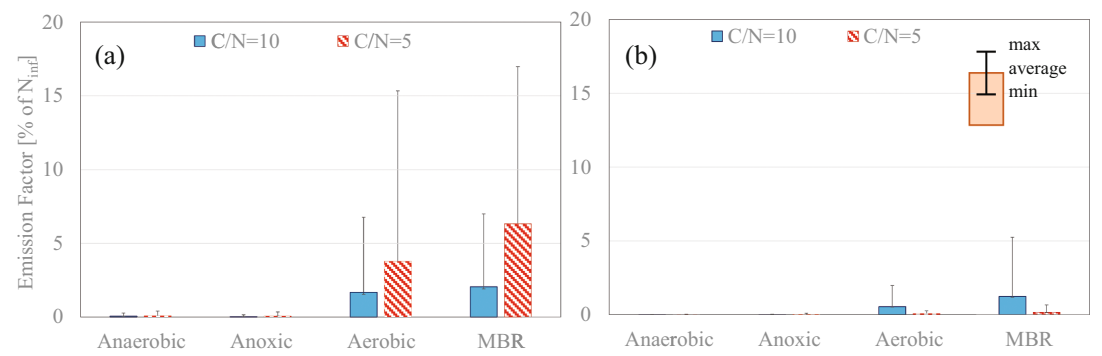

Fig. 2. Average Nitrous oxide Emission factors assessed during UCT-MBR (a) and during IFAS-UCT-MBR (b) for both investigated $\mathrm{C} / \mathrm{N}$ values.

For both configurations, the largest part of emission occurred from the aerated reactors (Fig. 2). However, the aerated reactors of the UCT-MBR configuration emitted much more than that of the IFAS-UCT-MBR configuration. Specifically, on average $3.5 \%$ of the influent nitrogen was emitted as $\mathrm{N}_{2} \mathrm{O}$ from the UCT-MBR plant and $0.5 \%$ (of the influent nitrogen) from IFAS-UCT-MBR plant. The presence of biofilm and suspended biomass in the IFAS-UCT-MBR plant has improved the nitrogen removal processes efficiency resulting in a sharp reduction of the $\mathrm{N}_{2} \mathrm{O}$ emission factor.

\section{Conclusions}

The comparison of two plant configurations (UCT-MBR and IFAS-UCT-MBR) under two different influent $\mathrm{C} / \mathrm{N}$ ratio (5 and $10 \mathrm{mgCOD} / \mathrm{mgN}$ ) has been performed. The IFAS-UCT-MBR configuration provided the best results in terms of pollutants removal 
performance during both the two investigated $\mathrm{C} / \mathrm{N}$ values. Furthermore, the lowest $\mathrm{N}_{2} \mathrm{O}$ emission (with respect to the influent nitrogen) occurred for the IFAS-UCT-MBR. However, the IFAS-UCT-MBR showed a greater tendency of being fouled respect to the UCT-MBR configuration. This result could have serious effects in terms of indirect GHG emissions due to the increase of the energy requirement for permeate extraction with the increase of membrane fouling.

Acknowledgments. This work forms part of a research project supported by grant of the Italian Ministry of Education, University and Research (MIUR) through the Research project of national interest PRIN2012 (D.M. 28 dicembre 2012 n. 957/Ric - Prot. 2012PTZAMC) entitled "Energy consumption and GreenHouse Gas (GHG) emissions in the wastewater treatment plants: a decision support system for planning and management - http://ghgfromwwtp.unipa.it" in which the first author is the Principal Investigator.

\section{References}

APHA (2005) Standard Methods for the Examination of Water and Wastewater. APHA, AWWA and WPCF, Washington DC, USA

Cosenza A, Di Bella G, Mannina G, Torregrossa M (2013) The role of EPS in fouling and foaming phenomena for a membrane bioreactor. Bioresour Technol 147:184-192

Kimochi Y, Inamori Y, Mizuochi M, Xu K-Q, Matsumura M (1998) Nitrogen removal and $\mathrm{N}_{2} \mathrm{O}$ emission in a full-scale domestic wastewater treatment plant with intermittent aeration. J Ferment Bioeng 86:202-206

Mannina G, Capodici M, Cosenza A, Di Trapani D (2016) Carbon and nutrient biological removal in a University of Cape Town membrane bioreactor: analysis of a pilot plant operated under two different C/N ratios. Chem Eng J 296:289-299

Mannina G, Capodici M, Cosenza A, Di Trapani D, van Loosdrecht MCM (2017) Nitrous oxide emission in a University of Cape Town membrane bioreactor: the effect of carbon to nitrogen ratio. J Cleaner Prod 149:180-190

Todt D, Dörsch P (2016) Mechanism leading to $\mathrm{N}_{2} \mathrm{O}$ production in wastewater treating biofilm systems. Rev Environ Sci Biotechnol 15(3):355-378

Tsuneda S, Mikami M, Kimochi Y (2005) Effect of salinity on nitrous oxide emission in the biological nitrogen removal process for industrial wastewater. J Hazard Mater 119:93-98

Wang XJ, Xia SQ, Chen L, Zhao JF, Renault NJ, Chovelon JM (2006) Nutrients removal from municipal wastewater by chemical precipitation in a moving bed biofilm reactor. Process Biochem 41(4):824-828

Wanner J (2002) Control of filamentous bulking in activated sludge. In: Bitton G (ed) Encyclopedia of environmental microbiology. John Wiley \& Sons Inc., New York, pp 1306-1315 